\title{
An Impact of CS Undergraduate Programming Skill on Career Development
}

\author{
Wanwipa Titthasiri \\ Department of Computer Science, Rangsit University, PathumThani, 12110, Thailand \\ wanwipat@gmail.com
}

\begin{abstract}
This study serves as a pilot study for a larger future study. The purpose of this pilot study was to find a relationship between programming skill and CGPA of CS graduates. Ten ICT managers of ICT firms were interviewed and 802 CS graduates' school records, from Rangsit University in Thailand were collected and analyzed. This pilot study reports the finding from both interviews and analysis of school records, detailing the critical skill-programming skill- of CS graduates, desirable in employment ICT workers. The results revealed that programming skill of CS graduates is today less than their academic performance. Consequently, ICT firms fail to fulfill the hopes of them. Finally, CS academic setting was discussed and proposed the roles of 3-levels-CS department chair, lecturers, and students-, playing to improve CS graduates' programming skill. Therefore, knowledge, ability and skill of CS graduates would meet ICT firms' requirements for future CS career development.
\end{abstract}

Keywords: CGPA, programming skill, career development, CS graduate.

\section{INTRODUCTION}

A production of high performance human resource has been seen as a vital role of higher educational institutions. E A. Plant et al [6] pointed that common measures of performance in college are the cumulated GPA (CGPA). Consequently, employers chose to focus on CGPA of graduates for their hiring. This study serves as a pilot study for a future study. It is to gain a benefit of the school academic setting on knowledge, ability, and skill. This research involves with CS (Computer Science) graduates who have been lacked in Thai workforce. It was reported that all of the existing CS graduates could not be developed becoming the ICT(Information and Communication Technology) professionals in their career.[11] Additionally, employers tend to be dissatisfied with skill, in particular the communication skill of new CS graduates.[10] Therefore, it is suspected by the researcher that CGPA-a representative of knowledge, ability, and skill- of graduates seems to be insufficient for measuring academic performance of CS graduates who will become to ICT professionals in their career path.

\section{OBJECTIVES}

Measuring skills of graduates received little attention compared to knowledge and ability, due to the difficulty in measuring. Nevertheless, skills have an impact on CS Career Development. The purpose of this pilot study is to find a relationship between technical skill, in particular programming skill and CGPA (academic performance). Implications of the findings for CS academic setting will be discussed.

\section{BACKGROUND}

\subsection{Department of Computer Science}

This pilot study was conducted in department of computer science, Rangsit University, Thailand. CS department was initiated in 1989. Its curricula was developed, based on the Associated for Computing Machinery (ACM) CS curriculum and be updated every five years, because of the rapidly changes in ICT. There are two programming fundamental courses for CS students to practice in the first year of program. As long as today, approximately $900 \mathrm{CS}$ graduates were produced into ICT market. CS department in Rangsit University is accepted as a front-runner in Thailand.

\subsection{Programming skill}

"Computer Science is the study of processes that interact with data and that can be represented as data in the form of programs... A computer scientist studied the theory of computation and the practice of designing software systems."[12] This definition shows that computer science deals with the theoretical knowledge and practices skills for software systems. According to CS work is mostly related to software systems and software development. It is pointed that even though CS is not

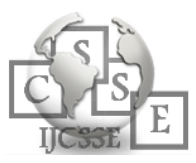


programming study, but programming is a vital tool in its study and career skills. Computer programming skill is the skill which is required for computer program according to given constraints and satisfying all test cases. Programming creates students' capability in software development.[11] Therefore, researcher realizes that if CS students graduated with less programming skill, then they would not be good or strong enough to meet requirements of ICT employers or organizations.

Additionally, C. L. Aasheim et al[3] conducted a survey of ICT managers and workers to examine their views on the knowledge and skills required of entry-level ICT workers. 348 responses from ICT managers and 238 responses from ICT workers were used for analysis. The findings were not surprising given that ICT firms rely heavily upon programming skills and system development methodologies to create and deploy ICT. Consequently, CS students who plan to seek employment in the ICT sector upon graduation should focus on programming skill apart from high CGPA in their CS courses.

"Computer programming learning is difficult and requires hard work from students. They need to do many exercises and create many programs to improve their programming competencies."[2] There are four primary steps in programming task, as follow:

(1) Problem-solving: analyzes the causes to the problem, generates a set of alternative solutions, and evaluates the best solution.

(2) Algorithm: transforms a selected solution into step by step.

(3) Coding: expresses idea of algorithm through programming languages.

(4)Debugging: be observant and more experience.

However, ComputerScienceZone [4] proposed ten skills to be needed by coders, as follow:

(1) Self-Reliance: focusses on what programming languages should coder use? And where to begin?

(2) Languages: learns at least one programming language for beginner.

(3) Logic: learns how to build up logic skills and problem-solving?

(4) Attention to detail:

(5) Recognition of stupidity: learns on computer's strength but dumb.

(6) Abstract thinking: presents on the object of thought-a foundation of coding.

(7) Patience:

(8) Strong memory:

(9) Scientific method:

(10) Communication and Empathy:

Generally, CGPA is used for measuring academic performance of graduates. However, ICT firms rely heavily upon programming skill to create and deploy
ICT. Consequently, researcher proposes to focus programming skill of CS graduates.

\section{RESEARCH METHODOLOGY AND RESULTS}

To study the programming skill as an important skill of CS students in their career path, an informal interview of ICT managers, as well as CS graduates' school records were collected and analyzed.

\subsection{Attitudes from Interviewees}

The researcher selected ten ICT managers who are the representative of a number of ICT firms, Seven are chosen from software houses, and the rests from computer vendors, company of network-solution, and company of users. The focus of these interviews was an importance of programming skill and CGPA of CS graduates, impacting on CS career development. The interview result supports the belief of researcher that programming skill is involved with the CS graduates' career development. All of interviewees agreed that most of CS graduates who have high grade points in programming skill would be able to work without any more training. They also pointed that not only CGPA is today used in considering of employment but also grade points in programming courses.

\subsection{Data analysis and Results}

Only school records of CS graduates were collected from Rangsit University, Thailand database. Student ID, CGPA and grade points of programming courses were compiled in Excel format. Data were collected from academic year 1994-2016, resulting in 802 CS graduates. They are grouped into 23 graduate's generations. The average of CGPA and the average of grade points of programming courses were computed in each graduate's generation, respectively. Thus, 23 averages of CGPA and 23 averages of grade points of programming courses were chosen as a representative of each generation. The first step of analysis, data was analyzed by M/S Excel. The mean of CGPA and grade point average of programming courses on CS graduates and p-value were computed by T-Test. A T-Test comparison analysis was performed in order to examine the differences between two variables of graduates. The effect of mean grade points was not significant at 0.05. ( $95 \%$ confidence interval ) ( $\mathrm{p}$-value $=0.134$ is greater than 0.05$)$ The hypothesis was accepted. There are no differences on grade point averages. However, the statistics revealed that mean CGPA (2.618) are higher than mean GPA produced by programming courses (2.523). Thus, the next step was to clarify. CGPA and GPA of

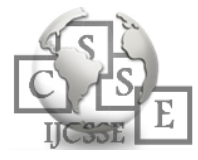


programming courses of 23 graduates' generations were plotted in line graph, as shown in Fig. 1.

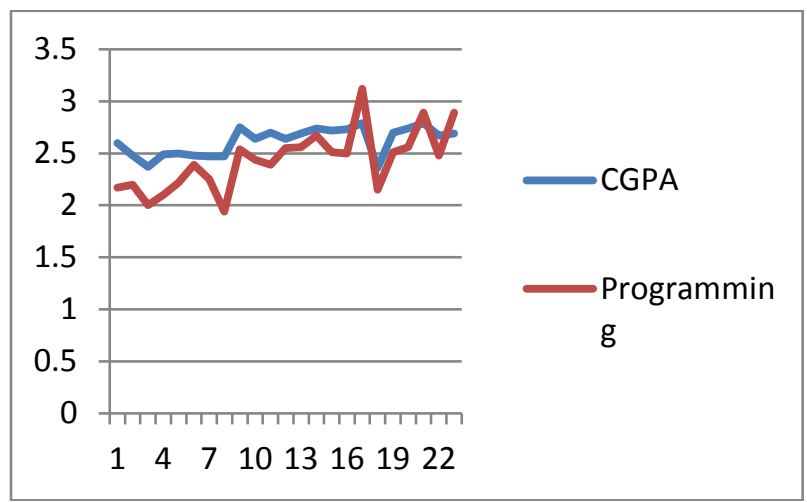

Fig. 1 A comparison of the average of CGPA and the average of grade point of programming courses, grouped by 23-CS graduate's generations.

Fig. 1 shows that both of lines go the same way. This means that if a student graduated with high CGPA then he or she would be expected to have a good programming skill. However, they were not overlapping line, even in a little difference. Thus, almost CS graduates could not be expected to have good programming skill as same as their academic performance, indicated CGPA. In order to improve academic performance of the CS graduates, programming skill should be focused to reduce a gap between programming grade points and CGPA. Consequently, ICT firms would be willing to use only CGPA, indicating academic performance of CS graduates in employment. It can be seen that academic performance (CGPA) could be worthy of CS graduate's rank without any more considering. To meet anticipated demand, it is urgent for CS program to prepare CS graduates with a better programming skill, due to an impact of programming skill on career development. Thus, it is better to remedy the situation of the need of stronger programming skill support for CS graduates. At least, CS graduates will be a completeness of knowledge, ability, and skill.

\section{DISCUSSION}

In this section, the improvement of programming skill will be discussed. Some actions would be proposed as a guideline for CS department chair, lecturers as well as students to follow. They can be summarized as follow:

(1) Administrative level:

There was a clear relationship between academic performance and programming skill of CS graduates. Programming skill was lower than academic performance, even in not much, but it's really less. CS department chair has to reduce this gap through a good planning in curricula, lecturers, budgets, and laboratory facilities supports. This level is as a strong base for achievement in academic performance. In addition, CS department chair has a duty of choosing the appropriate lecturers who have strong enough in programming skill and teaching experience for programming courses.

(2) Teaching Level:

This level is involved with lecturers, designing and teaching in programming courses. This one is huge, focusing on programming language selection, how to build up students' logic skill? problem-solving, abstract thinking, scientific methods, and debugging. However, the greatest achievements in programming have been creating algorithms that get computers to think in more independent and positive ways.[4] Thus, the role of lecturers is very important, driving classes, motivating, and inspiring students to hard practice. Moreover, lecturers have to attend to detail in teaching-learning process towards the end of course. Some resources for beginners include the completely free "Code Academy", which has helped 24 million people begin their experience, "edx", founded by Harward and MIT, which offers 60 schools and "Git Hub", which gives students access to 500 free programming books that cover 80 different languages.[4] Pair programming should be used in the class for beginners and focused on practices rather than teaching (active learning). After some experience has been received by students, workshops and conferences on programming practices should be held in every week. A programming academy focusing on using the game programming materials might be organized, taught [9]. This is hoped to encourage students to increase participated in programming. Moreover, independent learning is an expectation in university.[5] Students spent less time on academics than socializing in their first year.[8] Consequently, orientation and advising system are needed to revisit inadequate selfregulated learning and target GPA in first year. Motivation processes enables students to maximize their career paths.[1] Lecturers should focus on developing intervention in term of learning how to learn programming courses and/or workshops should be designed specifically for CS students to provide them with helpful adjustment strategies.[1]

(3) Learning Level:

Programming is a skill which is one of crafts where people can never know everything.[7] The researcher agreed with Lasn [7] that students should code every day because it is a skill. It is required a ton of practices and making it a habit to code each day. Pair programming is a good way to learn each other. Another word is "learning by teaching and help other programmers". In order to be a master programmer, students have to put the extra effort in programming and be patient. 
Fig. 2 shows a 3-levels triangle of practices guideline to improve programming skill of CS graduates for reducing a gap between CGPA and grade points of programming courses.

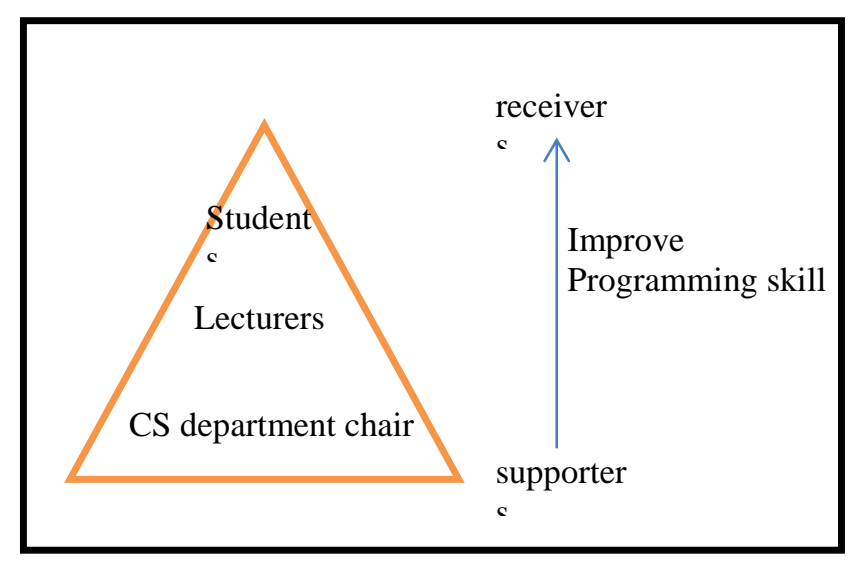

Fig. 2 A 3-levels triangle of CS students' programming practicing guideline.

\section{CONCLUSIONS}

This was a pilot study for what might be a larger study in the future. The focus was on a relationship between academic performance, indicated by CGPA and programming skill, indicated by grade points average of programming courses of CS graduates. The attitudes from interviewees show the weakness of CS graduates in term of programming skill. All of ICT managers fail to fulfill the hopes of CS graduates. This means that although CGPA of CS graduates is good, but they were still needed to have training for increasing programming skill. Meanwhile, the result of CS graduates' school records analysis supports them that grade point average of programming skill is lower than CGPA, even in going the same way. Thus, programming skill of CS graduates is considered as an impact factor in employment. These findings provided the information of "high academic performance but less programming skill" of CS graduates. This is an impact of programming skill on CS career development. At this point, CS education should be reviewed in order to reduce a gap between grade point average of programming courses and CGPA of CS graduates. Therefore, the necessity of the having of better programming skill in CS graduates is accepted by both CS department as a graduate producer and ICT firms as a graduate user. A 3-levels triangle of practices guideline to improve programming skill of CS graduates is discussed in this study responding CS employments demand.

\section{REFERENCES}

[1] A. Kitsantas, A. Winsler, and F. Hule, "Self-Regulation and Ability Predictors of Academic Success During College: A Prediction Validity Study", Journal of Advanced Academics, 2008.

[2] C. C. Areias, and A. Mendes, "A Tool to Help Students to Develop Programming Skills", in International Conference on Computer Systems and Technologies, 2017.

[3] C. L. Aasheim, R.W. Susan, S. B. Eulous, " Knowledge and Skill Requirements for Graduates", Journal of Computer Information Systems, Vol.49, No. 3, 2009, pp.48-53.

[4] ComputerScienceZone,'Ten Skills Needed by Coders". Available at: https://www.computersciencezone.org/10skills-necessary-coding/

[5] C. Robinson, and J. Gahagan, "Coaching Students to academic Success and Engagement on Campus", SAGE journals, 2010.

[6] E. A. Plant, K. A. Elicson, L. Hill, and K. Asberg, "Why Study time Does Not Predict Grade Point Average Across College Students: Implications of Deliberate Practice For Academic Performance", Contemperary Educational Psychology, Vol. 30, 2005, pp.96-116.

[7] I. Lasn, "Better Programming". Available at: https://medium.com/betterprograming/how-you-can-improve-our-programmingskilss-a439d47e26a4

[8] J. Thibodeaux, A. Deutsch, and A. Kitsantas, "First-year College Students' Time Use: Relations With SelfRegulation and GPA", Journal of Advanced Academics (SAGE Journal),2016.

[9] P. Doerschuk, L. Jiangjiang, and M. Judith, "An INSPIRED Game Programming Academy for High School Students", IEEE, 2017.

[10] W. Titthasiri, "Fostering New Computer Science Graduates Capabilities Through Software Engineering Class", International Journal of Computer Science and Software Engineering, Vol. 6, No. 2, 2017, pp.36-40.

[11] W. Titthasiri, "The Challenging Development of ICT Professionals and Thailand 4.0 Success: A Prediction of Academic Performance of CS Graduates", Journal of Engineering Research and Application, Vol.9, No.3(Series-II), 2019, pp.88-92.

[12] Wikipedia. "Computer Science Definition" Available at: "http://en.m.wikipedia.org" 